\title{
Surgical excision of right ventricular carcinoid tumor in a symptomatic patient without carcinoid valve disease
}

\author{
Basar Sareyyupoglu, MD, ${ }^{\mathrm{a}}$ Heidi M. Connolly, MD, ${ }^{\mathrm{b}}$ and Hartzell V. Schaff, MD, ${ }^{\mathrm{a}}$ Rochester, Minn
}

This report describes the unusual presentation of a 55-yearold man with normal cardiac valves who had metastatic carcinoid tumor in the heart. The patient underwent coronary artery bypass grafting at another hospital in 1982. In 2004 he had partial colectomy for tumor removal, and pathologic examination disclosed carcinoid cell type. Hepatic metastases were treated with arterial embolization. At the time of evaluation at the Mayo Clinic, he did not report diarrhea but had noticed increasing frequency of facial flushing; he had started taking somatostatin 4 months earlier. A computed tomography scan in March of 2008 demonstrated a tumor in the mediastinum, and this was a new finding compared with a similar study in September 2005. The 4- to 5-cm mass compressed the right ventricle (Figure 1, $A, B$ ). In addition to worsening flushing, he had symptoms of presyncope, shortness of breath, and limited exercise capacity. His echocardiogram showed no evidence of valvular disease, and his left ventricular function was normal.

\section{CLINICAL SUMMARY}

The patient was advised to undergo excision of the right ventricular tumor. After a repeat median sternotomy was made, the left-sided saphenous vein was identified and preserved. There was a $3.5 \times 4.5$-cm tumor in the free wall of the right ventricle. A thin layer of muscle and fat covered the tumor (Figure 2, $A$ ), and the mass projected into the ventricle over a small area. Cardiopulmonary bypass was initiated by using an inflow arterial cannula in the ascending aorta and an outflow single 2-stage venous cannula in the right atrium. The heart was allowed to beat rhythmically while the tumor was removed; we dissected over the tumor in the right ventricle, making an oblique incision in the line of the muscle fibers. Most of the tumor was within the right ventricular muscle, and there was a capsule around the tumor (Figure 2,B), which was removed completely by using a combination of sharp and blunt dissection (Figure 2, $C, D$ ). Removal of the mass

From the Divisions of Cardiovascular Surgery ${ }^{\mathrm{a}}$ and Cardiovascular Diseases, ${ }^{\mathrm{b}}$ Mayo Clinic, Rochester, Minn.

Disclosures: None.

Received for publication July 20, 2009; accepted for publication July 31, 2009; available ahead of print April 5, 2010.

Address for reprints: Hartzell V. Schaff, MD, Mayo Clinic, Cardiothoracic Surgery Department, Joseph 5-200, 200 First Street SW, Rochester, MN 55905 (E-mail: schaff@mayo.edu).

J Thorac Cardiovasc Surg 2010;140:e23-5

$0022-5223 / \$ 36.00$

Copyright $(C 2010$ Published by Elsevier Inc. on behalf of The American Association for Thoracic Surgery

doi:10.1016/j.jtcvs.2009.07.072
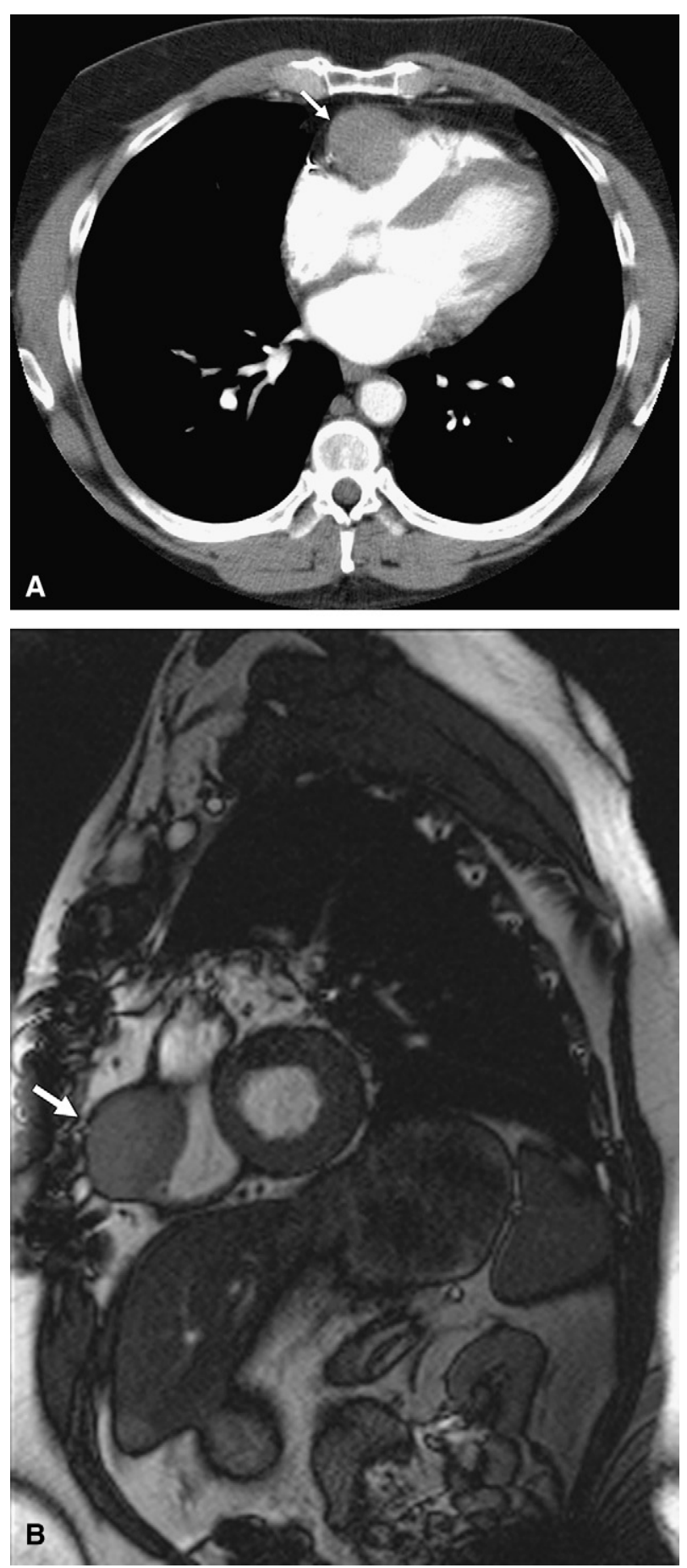

FIGURE 1. A, Computed tomography in patient taken in horizontal long axis derivation and (B) magnetic resonance angiography cine taken in lateral short axis derivation showing tumor (arrows) compressing right ventricular outflow tract. 

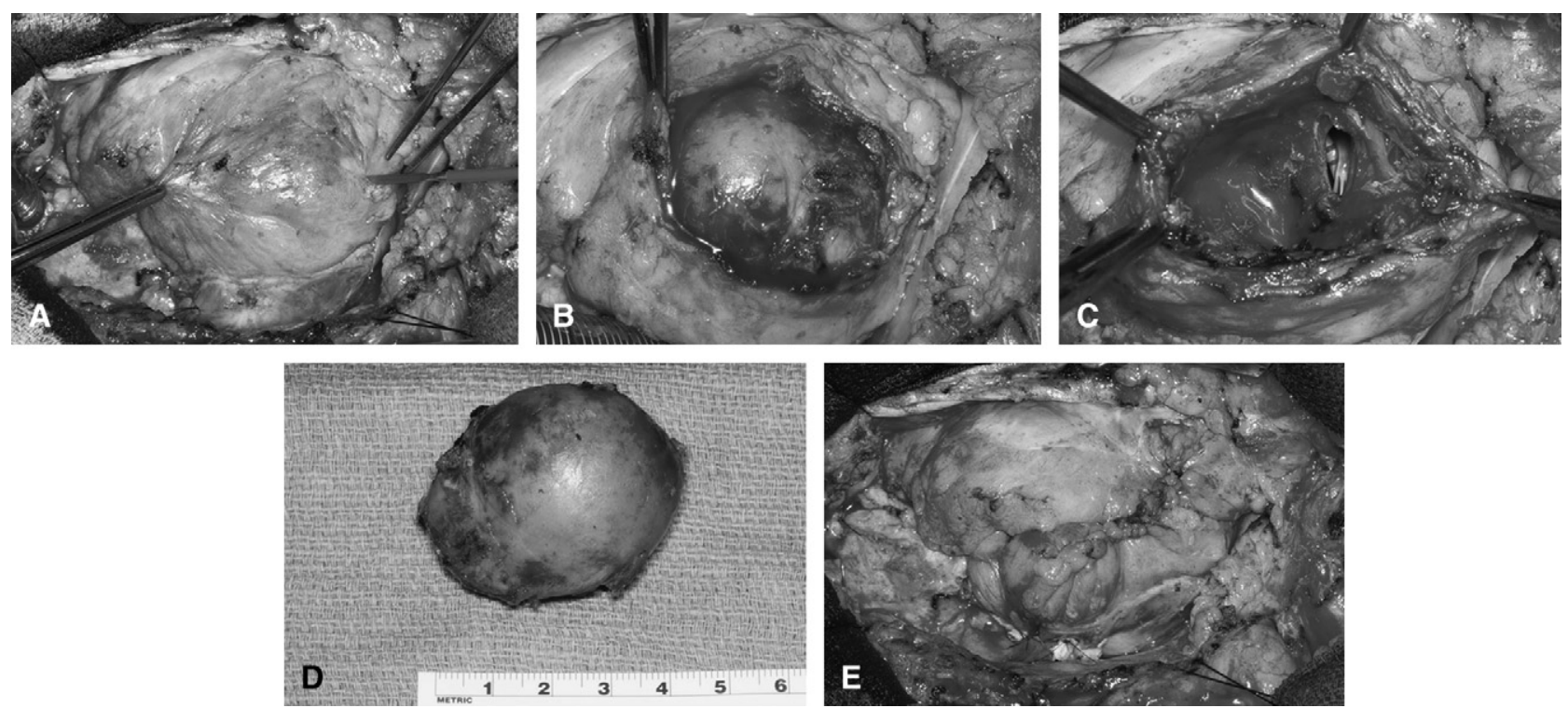

FIGURE 2. Operative excision of the carcinoid tumor. A, Tumor covered with thin epicardial fat and muscle projecting on the right venricle. B, Capsulated tumor within the ventricle. C, Removal of the tumor resulted in a 2-cm diameter communication with the right ventricular cavity; Swan catheter is seen through the communication. D, Gross appearance of the resected tumor. E, Primary closure of the epicardial layer.

resulted in a $2-\mathrm{cm}$ diameter communication with the right ventricular cavity (Figure 2,C); this was closed with 2 pledgeted 3-0 Prolene sutures. The remainder of the bed of the tumor within the right ventricular muscle was obliterated with interrupted 3-0 Prolene sutures, and the epicardial layer was closed in 2 layers with 3-0 Prolene sutures (Figure 2, E).

The patient's recovery was uncomplicated, and a followup computed tomography scan 1 year postoperatively showed no recurrence or additional metastases. Fifteen months postoperatively, the patient is still receiving octreotide and reports no symptoms.

\section{DISCUSSION}

Breast, lung, and malignant melanomas are the most common primary tumors that metastasize the heart. ${ }^{1}$ Carcinoid tumors are rare, arising in 1.2 to 2.1 per 100,000 persons in the general population per year. ${ }^{2}$ Flushing, gastrointestinal hypermotility (secretory diarrhea), bronchospasm, and carcinoid heart disease are the common presentations of the malignant carcinoid syndrome. The diagnosis of carcinoid syndrome is usually suspected by clinical features and confirmed by increased levels of the by-product of serotonin metabolism, 5-hydroxyindoleacetic acid. Right-sided valvular dysfunction is the pathognomonic feature of carcinoid heart disease. There has been only 1 series reporting the clinical and tumor characteristics along with echocardiographic and pathologic features of metastatic carcinoid to the heart. ${ }^{3}$ Of the 243 patients seen with carcinoid heart disease from 1985 to 1999 at the Mayo Clinic, $11(4 \%)$ were identified as having metastatic carcinoid tumor involving the heart, and among those, only 6 underwent surgical excision of the tumor; in the remaining 5 patients, diagnosis was made at autopsy. ${ }^{3}$ On echocardiographic evaluation, metastatic carcinoid tumor appears as a homogeneous, circumscribed, noninfiltrating mass affecting the left or right ventricular myocardium. Although metastatic carcinoid tumor is uncommon, it has echocardiographic characteristics that make it easily identifiable when it is $1.0 \mathrm{~cm}$ or larger.

In a study with 100 consecutive patients who underwent cardiac surgery for carcinoid disease, Weingarten and associates ${ }^{4}$ emphasized that hypotension in patients with carcinoid heart disease should be treated with octreotide, but vasoactive medications can be safely administered for refractory hypotension in the presence of octreotide. Although our patient had received his monthly long-acting dose of octreotide treatment, during the operation and on manipulation of the mass on cardiopulmonary bypass, additional doses of octreotide up to $4000 \mu \mathrm{g}$ were needed for hemodynamic support and brief periods of hypotension.

\section{CONCLUSIONS}

Metastatic carcinoid tumor may be the only manifestation of carcinoid heart disease. The comprehensive echocardiographic assessment of a patient with carcinoid disease should include a search for carcinoid metastases, even in the absence of carcinoid valvular disease. ${ }^{3}$ As demonstrated by our patient, metastatic carcinoid disease in the myocardium may cause symptoms that are ameliorated by tumor removal.

\section{References}

1. Hall RJ, Cooley DA, McAllister HA Jr, et al. Neoplastic heart disease. In: Schlant RC, Alexander RW, eds. The heart: arteries and veins. New York, NY: McGraw-Hill; 1994:2011-9. 
2. Modlin IM, Sandor A. An analysis of 8305 cases of carcinoid tumors. Cancer. 1997;79:813-29.

3. Pandya UH, Pellikka PA, Enriquez-Sarano M, Edwards WD, Schaff HV, Connolly HM. Metastatic carcinoid tumor to the heart: echocardiographic-pathologic study of 11 patients. J Am Coll Cardiol. 2002;40:1328-32.
4. Weingarten TN, Abel MD, Connolly HM, Schroeder DR, Schaff HV. Intraoperative management of patients with carcinoid heart disease having valvular surgery: a review of one hundred consecutive cases. Anesth Analg. 2007;105: 1192-9.

\title{
Use of a hybrid operating room to diagnose and treat delayed coronary spasm after mitral valve repair
}

\author{
Jared L. Antevil, MD, Alexandros N. Karavas, MD, John H. Selby, MD, and John G. Byrne, MD, \\ Nashville, Tenn
}

We describe a case of delayed circulatory collapse after mitral valve repair caused by diffuse coronary artery vasospasm. The cause and management of this condition are discussed.

\section{CLINICAL SUMMARY}

A 66-year-old woman presented with severe symptomatic mitral valve regurgitation. Although cardiac catheterization revealed no significant epicardial coronary artery disease, the patient was taking long-acting oral nitrates and calcium antagonists for recurrent nonexertional chest pain and a presumed diagnosis of variant angina. At the time of the operation, inspection of the mitral valve revealed myxomatous characteristics with a redundant posterior leaflet, an associated posterior leaflet cleft, and override of the anterior leaflet. Repair was performed by using primary suture closure of the cleft, followed by annuloplasty with a 30-mm CosgroveEdwards device (Edwards Lifesciences, Irvine, Calif). A postrepair transesophageal echocardiogram revealed trivial residual mitral valve regurgitation and preserved biventricular function, without significant transmitral or subaortic gradients.

The patient was off all vasoactive medications (which included norepinephrine) within 3 hours of her operation and was extubated uneventfully that afternoon. Shortly after mediastinal tube removal the following day (28 hours postoperatively), she experienced chest pain and a precipitous decrease in her systolic blood pressure to $60 \mathrm{~mm} \mathrm{Hg}$. Her cardiac index decreased to $0.7 \mathrm{~L} \mathrm{~min}^{-1} \mathrm{~m}^{-2}$, and her central venous pressure of $23 \mathrm{~mm} \mathrm{Hg}$ was identical to her diastolic pulmonary artery pressure.

\footnotetext{
From the Vanderbilt Heart and Vascular Institute, Nashville, Tenn. Disclosures: None.

Received for publication June 10, 2009; revisions received July 14, 2009; accepted for publication July 31, 2009; available ahead of print Sept 27, 2009.

Address for reprints: John G. Byrne, MD, Vanderbilt University Medical Center, Nashville, TN 37232-8802 (E-mail: john.byrne@vanderbilt.edu).

J Thorac Cardiovasc Surg 2010;140:e25-7

$0022-5223 / \$ 36.00$

Copyright (C) 2010 by The American Association for Thoracic Surgery

doi:10.1016/j.jtcvs.2009.07.074
}

Surface echocardiographic analysis during preparations to reopen her chest for suspected tamponade revealed severe global hypokinesis of both ventricles, with a left ventricular ejection fraction of less than $10 \%$. The patient's mitral valve repair appeared to be intact. Mediastinal exploration revealed no evidence of bleeding, tamponade, or other surgical complications. She was taken on an emergency basis to the hybrid operating room-catheterization laboratory for further evaluation and treatment. The diagnoses of left circumflex coronary artery injury or coronary thrombus were entertained. The patient was supported with intravenous infusions of epinephrine, dopamine, and norepinephrine en route to the hybrid operating room.

Open-chest intraoperative coronary angiographic analysis was initiated, but engagement of the left coronary artery resulted in pressure dampening and a sudden decrease in blood pressure. After placement of a femoral intra-aortic balloon pump (IABP), coronary angiographic analysis revealed diffuse severe stenosis of the left anterior descending and right coronary arteries, which is consistent with coronary vasospasm (Figure 1). With intracoronary nitroglycerin infusion into both the left and right coronary systems and a reduction in the patient's adrenergic medications, the patient's vasospasm improved but did not completely resolve. Infusions of milrinone and nitroglycerin were initiated, the patient's norepinephrine was weaned to $5 \mu \mathrm{g} / \mathrm{min}$, and her chest was closed.

Over the next week, the patient demonstrated steady hemodynamic improvement. Repeated echocardiograms demonstrated normalization of biventricular function, and her IABP was removed 4 days after her reoperation. The patient was restarted on a long-acting oral nitrate and calcium antagonist. She was discharged home 20 days after her original operation and has been free of dyspnea and angina to date.

\section{DISCUSSION}

Although it is likely underrecognized, clinically significant coronary vasospasm has been reported to occur after 